\title{
Evidencias de arquitectura de materiales perecederos en Buenos Aires, Argentina (siglos XVI-XVIII)
}

\section{Evidences of architecture made with perishable materials at Buenos Aires, Argentina (16 to $18^{\text {th }}$ centuries)}

\author{
Daniel Schávelzon \\ Centro de Árqueología Urbana, Universidad de Buenos Aires \\ Conicet \\ e-mail: dschavelzon@fibertel.com.ar
}

\section{RESUMEN}

La población indígena que ocupaba el lugar donde en 1580 se fundara Buenos Aires siempre ha sido considera como nómade o semi-nómade. Eso ha sido interpretado como que no tenía ninguna forma de arquitectura, o que lo que usaron no dejaba huellas que la arqueología pudiese recuperar. Una revisión de los estudios ya hechos en la ciudad muestra al menos dos casos en que una serie de agujeros de poste ubicados en líneas podría indicar la probable presencia de los llamados toldos indígenas. Es decir, evidencias de haber existido construcciones hechas con postes verticales y cerrados con ramas, paja o cueros de vacas o caballos tal como consta en la documentación histórica, los que subsistieron en regiones cercanas hasta finales del siglo XIX.

Pero también es posible que haya sido algún tipo de arquitectura maderera muy modesta de los criollos pobres, aunque la materialidad cultural tiene a confirmar la primera hipótesis.

Palabras clave: Buenos Aires; arquitectura indígena; arqueología histórica; huellas de postes.

\begin{abstract}
The indigenous population occupying the place where Buenos Aires was founded in 1580 has always been seen as nomadic or semi-nomadic. This has been interpreted as having no form of architecture, or what used left no traces that archeology could recover. A review of studies already done in the city shows at least two cases in which a series of postholes located in lines could indicate the likely presence of so-called indigenous awnings. That is evidence of having been made constructions with vertical posts and closed with branches, straw or hides of cows or horses as recorded in historical documentation, which subsisted in others regions until the nineteenth century.

But it also may have been some kind of very modest timber of the poor Creole architecture, although cultural materiality has to confirm the first hypothesis.
\end{abstract}

Keywords: Buenos Aires; indigenous architecture; historic archaeology; post holes.

Recibido: 15-09-2015. Aceptado: 06-05-2016.

Cómo citar este artículo / Citation

Schávelzon, D. 2016: "Evidencias de arquitectura de materiales perecederos en Buenos Aires, Argentina (siglos XVI-XVIII)", Arqueología de la Arquitectura, 13: e041. doi: http://dx.doi.org/10.3989/arq.arqt.2016.004

\section{Copyright}

(c) 2016 CSIC. Este es un artículo de acceso abierto distribuido bajo los términos de una licencia de uso y distribución Creative Commons Attribution (CC-by) España 3.0. 


\section{INTRODUCCIÓN}

Resulta un ejercicio intelectual interesante el revisar lo que uno mismo excavó hace años, sea en base a hallazgos que lo reiteran o a interpretaciones recientes que le dan nuevos significados. Es decir, el presente que nos obliga a revisar el pasado para avanzar sobre un nuevo presente. Eso puede significar reconocer errores cuando simplemente es aceptar que hay cosas a las que no se le prestó la suficiente atención porque las condiciones no estaban dadas, porque no entraban en los paradigmas vigentes. Otra mirada sería el aceptar que en las excavaciones grandes como es los casos de edificios urbanos, o de espacios muy amplios, trabajos siempre hechos con tiempos y recursos mínimos, y en los momentos iniciales de una actividad compleja como fue arqueología urbana, era tanto lo que se veía que era imposible darle importancia a todo. Hay cosas que uno deja de lado porque ya llegará su tiempo y uno discrimina lo que se considera significativo, en especial en operaciones de rescate o salvamento.

Estos casos que presentamos fueron rasgos arqueológicos, otro dato más en excavaciones complejas, pero que ahora y en base a nuevas evidencias se tornan significativos. Se trata de revisar algunos pequeños agujeros de postes encontrados en pisos de tierra, probables productos de la antigua existencia de arquitecturas. Si bien fueron relevados y documentados nunca se los puso en un contexto específico o se trató de interpretarlos. Los más complejos provienen de la excavación de la Imprenta Coni que se hizo hace varios años, ubicada en la calle Perú 680 (Schávelzon 1995). Lo que nos llevó a repensarlos fue el encontrar en fecha reciente algo parecido en el patio de la llamada Casa del Virrey Liniers, por cierto a poca distancia una de la otra (Hernández de Lara, Odlanyer y Schávelzon 2014).

\section{LA EXCAVACIÓN EN SUPERFICIE ABIERTA (OPEN AREA)}

Los primeros pozos que evidenciaban ser restos de postes en esa excavación eran sólo tres de ellos alineados, algo poco significativo en ese contexto de una casa de mampostería de ladrillos encima de otra por dos siglos. El hallazgo resultó ser el producto del uso de una técnica de excavación nueva en su tiempo al menos en la arqueología histórica nacional, del paso de la cuadrícula y las deformaciones en el registro que producía, al que se llama localmente como de Área Abierta (Open área, o en España Superficie abierta). La presencia de estos agujeros identificados desde el inicio como de postes no fue llevada más lejos porque nadie se imaginaba su alcance, tanto porque la bibliografía disponible no tomaba en consideración ese tipo de situaciones, como porque nadie había hablado jamás de la posibilidad de la presencia de toldos indígenas en la ciudad. Sólo las publicaciones posteriores sobre arqueología de la arquitectura, llegadas desde el exterior, nos hicieron entender la importancia de este tipo de evidencia. Entendemos la palabra "toldo" o "toldería" como una construcción indígena en que el cerramiento se hacía con cueros de animales, términos que se remontan hasta el siglo XVI. No tenemos evidencias materiales que demuestren que este tipo de construcción se usaba en tiempos prehispánicos, pero es muy posible que así haya sido (Fig. 1 y Fig. 2). Lo interesante en este caso es que la construcción posterior, de criollos y blancos, también la usó y en las zonas inundables isleñas cercanas a Buenos Aires sigue en uso (Fig. 3 y Fig. 4).

En 1989 al excavarse la Imprenta Coni nos atrevimos a experimentar con dos avances: trabajar en Open Area y a usar el llamado Método de Harris ${ }^{1}$ (1991) que se había editado en inglés en 1979, pero la edición española sólo fue accesible a partir de 1991. El libro de Philip Baker con la manera de excavar sistemáticamente áreas abiertas, Techniques of Archaeological Excavations en el mundo local pre-internet era casi inexistente (Baker 1993). La primera edición fue de 1977 y Gran Bretaña era un país considerado como enemigo tras la Guerra de Malvinas, absurdamente ¿quién iba a importar libros de allí?, por lo que sólo se difundió con la tercera edición de 1987, y aun más tarde. Stanley South nos había enfrentado a sus grandes excavaciones en Carolina del Sur (a partir de 1990 estuvo en contacto estable con América Latina), lo que abrió la puerta a las técnicas de excavación de asentamientos históricos en Estados Unidos. Sabíamos que esto se hacía, pero en América Latina la tradición era absoluta y rígida, y las influencias mayores llegaban desde Estados Unidos y no de Europa. Los métodos diferentes de trabajo aun no se han instrumentado en una Argentina donde ni siquiera se usan las mismas herramientas de trabajo, como la pala sin mango para levantar grandes estratos abiertos.

Todo eso, la arqueología histórica, la arqueología urbana y el encarar la excavación de arquitecturas, era

\footnotetext{
${ }^{1}$ Fue usado por primera vez en las excavaciones de la calle Defensa 755 en 1987, actualmente conocido como Zanjón de Granados.
} 


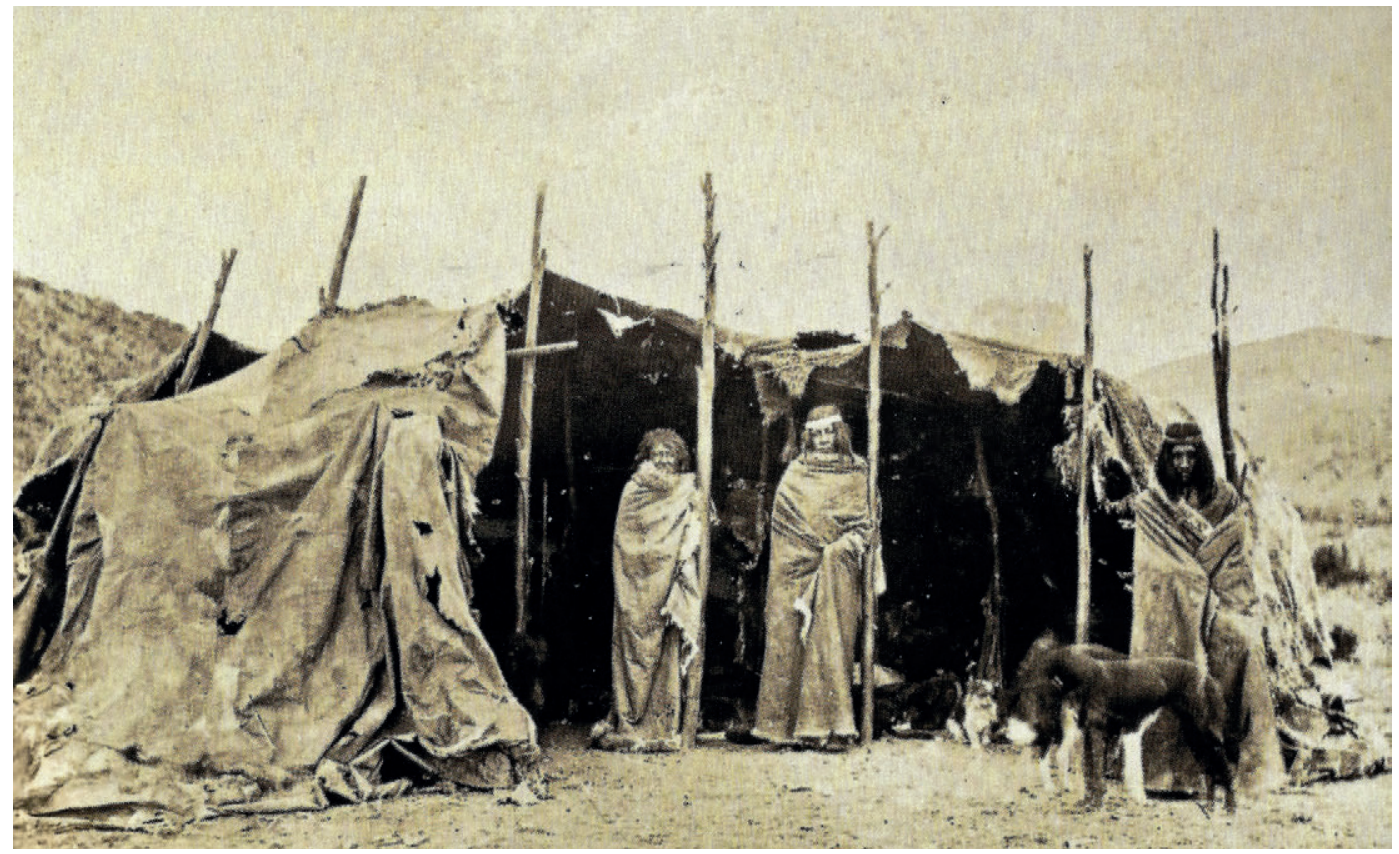

Fig. 1. Toldo tehuelche en 1874, nótese el sistema estructural de postes en hileras paralelas, posible tradición prehispánica de construcción (Mondelo 2012: 73).
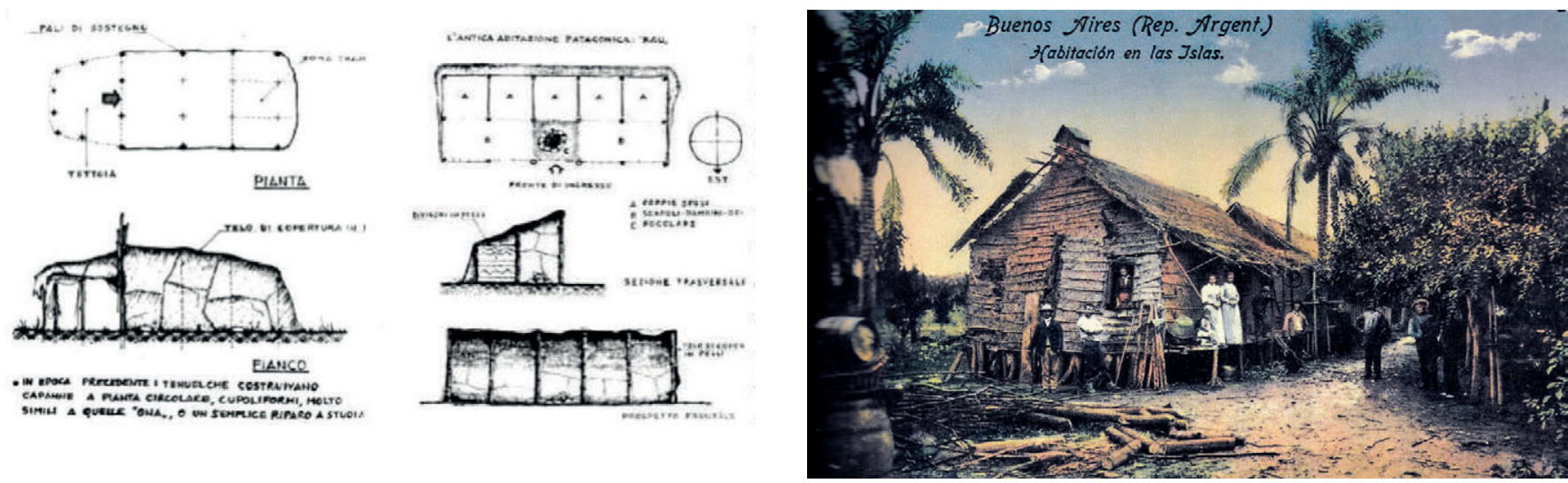

Fig. 2. Sistemas constructivos de toldos de la región patagónica: dos interpretaciones diferentes sobre la misma estructura de postes (Casamiquela 2000: fig. 2).

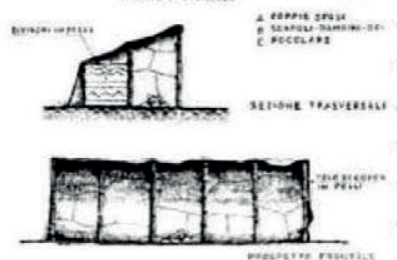

Fig. 3. Casa construida sobre postes de madera, tradicional entre los inmigrantes asentados en la región isleña al norte de la ciudad, foto 1902 (Colección privada, Buenos Aires).

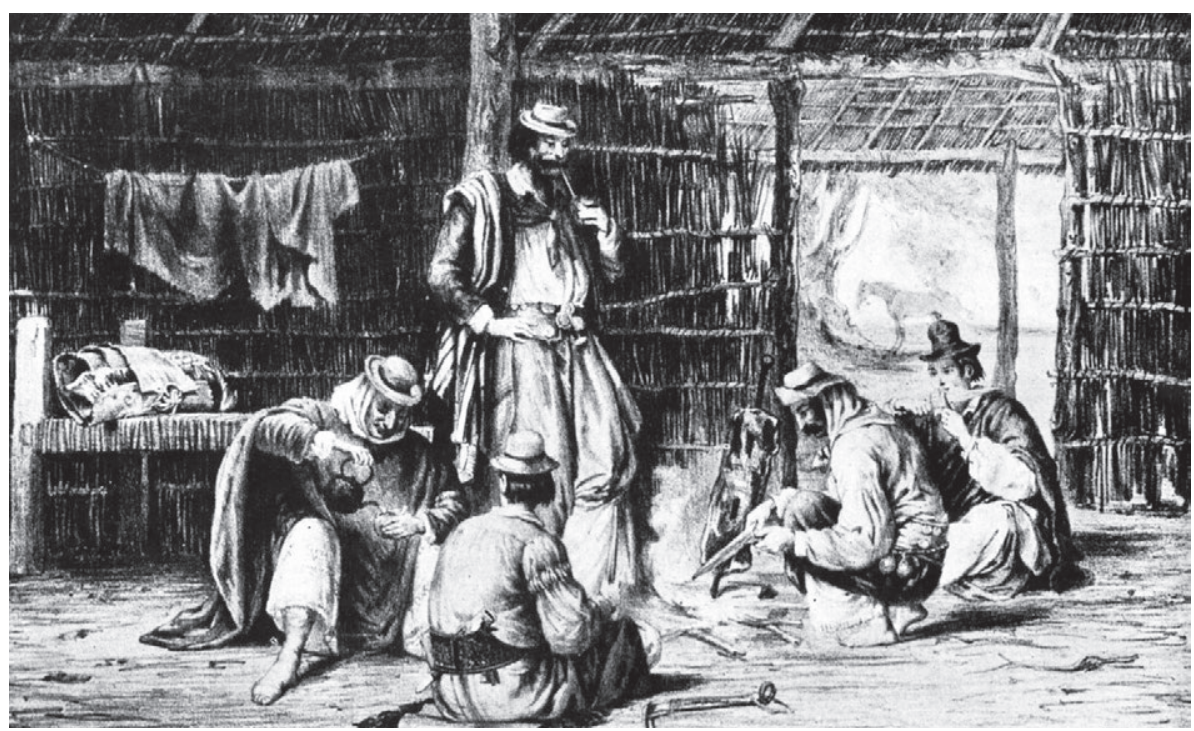

Fig. 4. Rancho de los alrededores de Buenos Aires en un grabado de León Palliere hacia 1830, la colocación de los postes es siempre regular con un habitual poste central y un alero en la entrada. 
ya demasiado trabajo para un grupo de jóvenes como para observar simples agujeros de poste aun sin un significado establecido y reconocido. La existencia de publicaciones sobre arqueología de la arquitectura era impensable localmente hasta finales de la década de 1990, y el inicio fue a través de la bibliografía italiana quizás por casualidad personal. El plano de South, por dar un ejemplo, del trabajo hecho en el Moundless Ceremonial Center en Albermarle Point en 1969, que aquí reproducimos, estaba más allá del límite de nuestra imaginación cuando nos lo presentó con otros más en 1990, aquí aun se discutía la pertinencia de la arqueología histórica (Rafinno e Igareta 2004; Igareta y Malbrán 2013)² (Fig. 5). Este tipo de excavaciones se comenzó a hacer en el país de forma sistemática en sitios históricos a partir de la intervención de Agustín Azkárate en las excavaciones de Puerto Gaboto en el año 2009, mostrando las enormes posibilidades que tenía el método por sobre las técnicas usadas antes (Letieri, Cocco, Frittegotto y Astiz 2010; Cocco, Letieri y Frittegotto 2011; Azkárate 2013).

\footnotetext{
2 Tuvimos acceso a ese y otros planos y libros de su trabajo a partir de 1995.
}

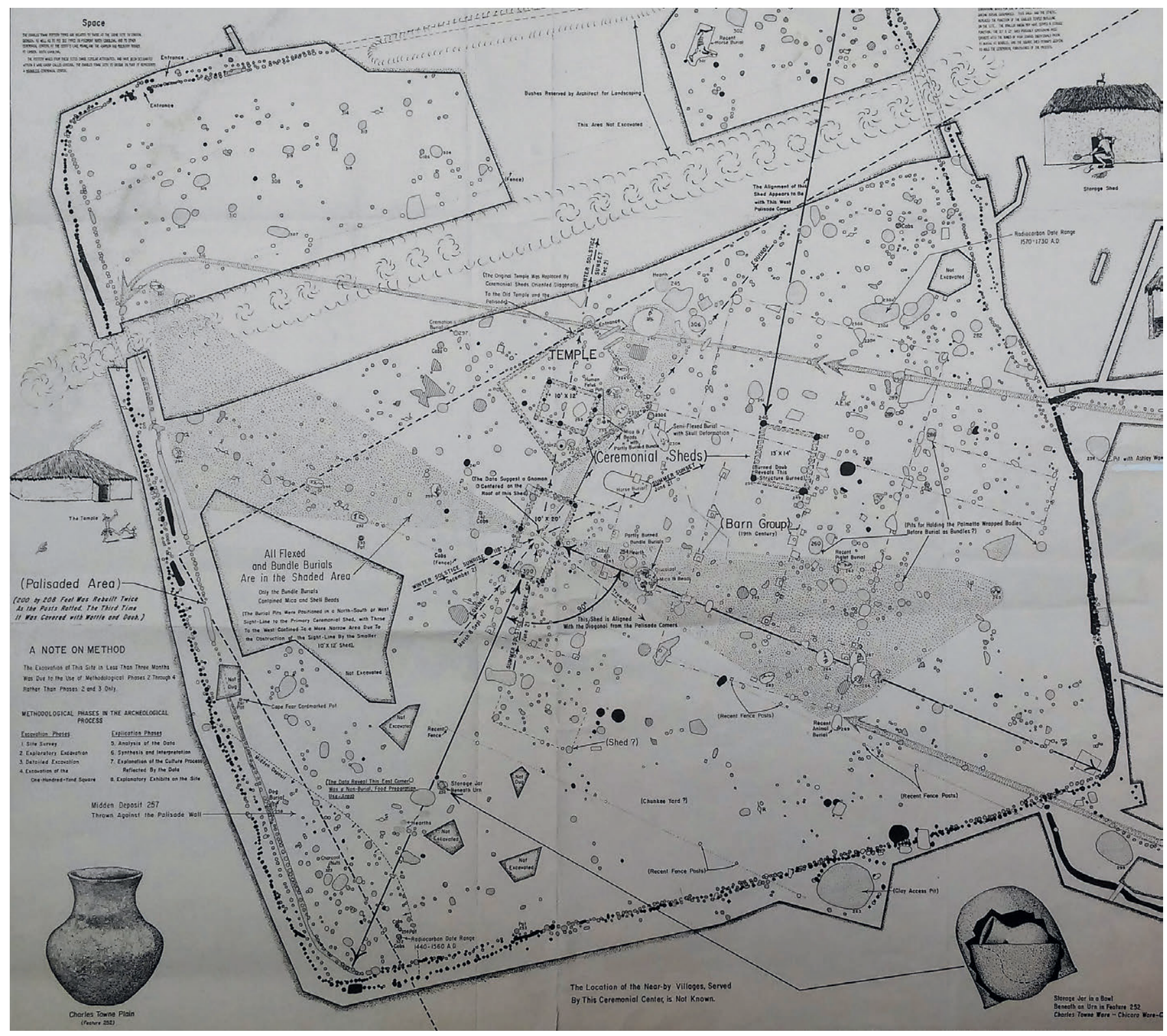

Fig. 5. Plano principal de la excavación de Stanley South en el Moundless Ceremonial Center en 1969 (Cortesía Stanley South). 


\section{LOS AGUJEROS DE POSTE}

Estas simples y modestas marcas en el espacio y en el tiempo sobre los suelos sugieren la posibilidad de repensar los orígenes de la vivienda en la región de la ciudad, y la existencia de arquitecturas de materiales perecederos, lo que es el inicio en un terreno del que nada sabemos. Es nuestra hipótesis asumir que los agujeros de poste encontrados hasta la fecha correspondan a arquitecturas no consideradas anteriormente.

Buenos Aires fue un primer establecimiento hecho por Pedro de Mendoza en 1536 aunque no sepamos aun cómo o dónde. En los pocos documentos existentes no se describe la existencia de viviendas indígenas con quienes tuvieron enormes dificultades, quienes se mantenían viviendo en sus aldeas jamás descritas. Ese asentamiento fue desmantelado en 1541 para volver a ser fundada la ciudad por Juan de Garay en 1580. Allí la traza urbana era exclusiva para españoles o criollos. Pero pese a la ley veremos más adelante que los indígenas sí construyeron y vivieron dentro de la traza urbana, pero no tenemos ninguna descripción concreta de una de estas obras más que el dato de su existencia y ser de "cueros".

Es decir que de ser nuestra hipótesis posible acerca de que líneas de agujeros de postes excavadas fueran indígenas o de arquitecturas perecedera criollas, podríamos estar frente a evidencias muy antiguas de la arquitectura local en el territorio hoy cubierto por la ciudad, sean previas o contemporáneas en el tiempo a la cuadrícula urbana española.

\section{LOS HALLAZGOS DE LA IMPRENTA CONI}

La excavación del edificio que ocupara durante siglo y medio la Imprenta Coni significó la apertura completa de varias habitaciones. La llamada Habitación I fue trabajada con el Método de Open Area por lo que se liberó el suelo totalmente hasta el nivel estéril (Fig. 6). Al excavarla se encontró, entre otras cosas, un cimiento hecho con ladrillos fragmentados y diferente a los demás que eran de ladrillos enteros, que se interpreta como a ser previo, a haber pertenecido a una pequeña casa anterior, y habría sido reusado. Fue identificado como perteneciente a la casa Rodríguez existente ya en 1740 según la documentación histórica. Ese cimiento cortaba una línea perpendicular formada por tres agujeros de postes (Fig. 7). Dos de ellos sólo contenían la tierra del estrato superior pero un tercero tenía una estratigrafía interna clara que incluía fragmentos de cerámica y restos de una astilla de hueso que pudo identificarse como de una costilla de mamífero grande, casi con seguridad un vacuno (Fig. 8). De esta forma los agujeros son previos a esa fecha aunque es imposible saber a cuándo se remontan, aunque luego analizamos en detalle las cerámicas y su fechamiento.

La posición de esos tres agujeros resulta interesante ya que son paralelos a la fachada del edificio actual, es decir en la línea norte-sur que es el trazado de la ciudad desde 1608. La ciudad original desconocemos cómo había sido

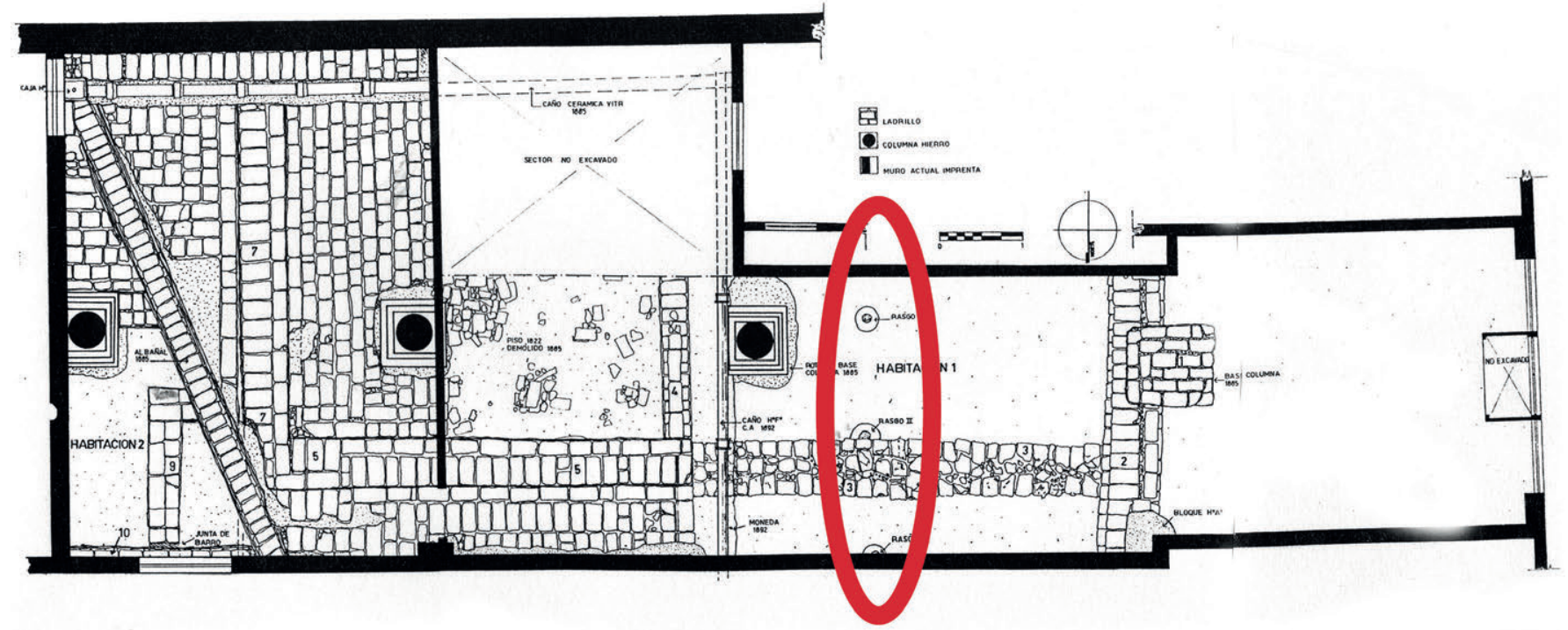

Fig. 6. Plano de las Habitaciones 1 y 2 de la Imprenta Coni tras su excavación en 1989, nótese la secuencia de agujeros de postes en dirección norte-sur cortados por un cimiento. 


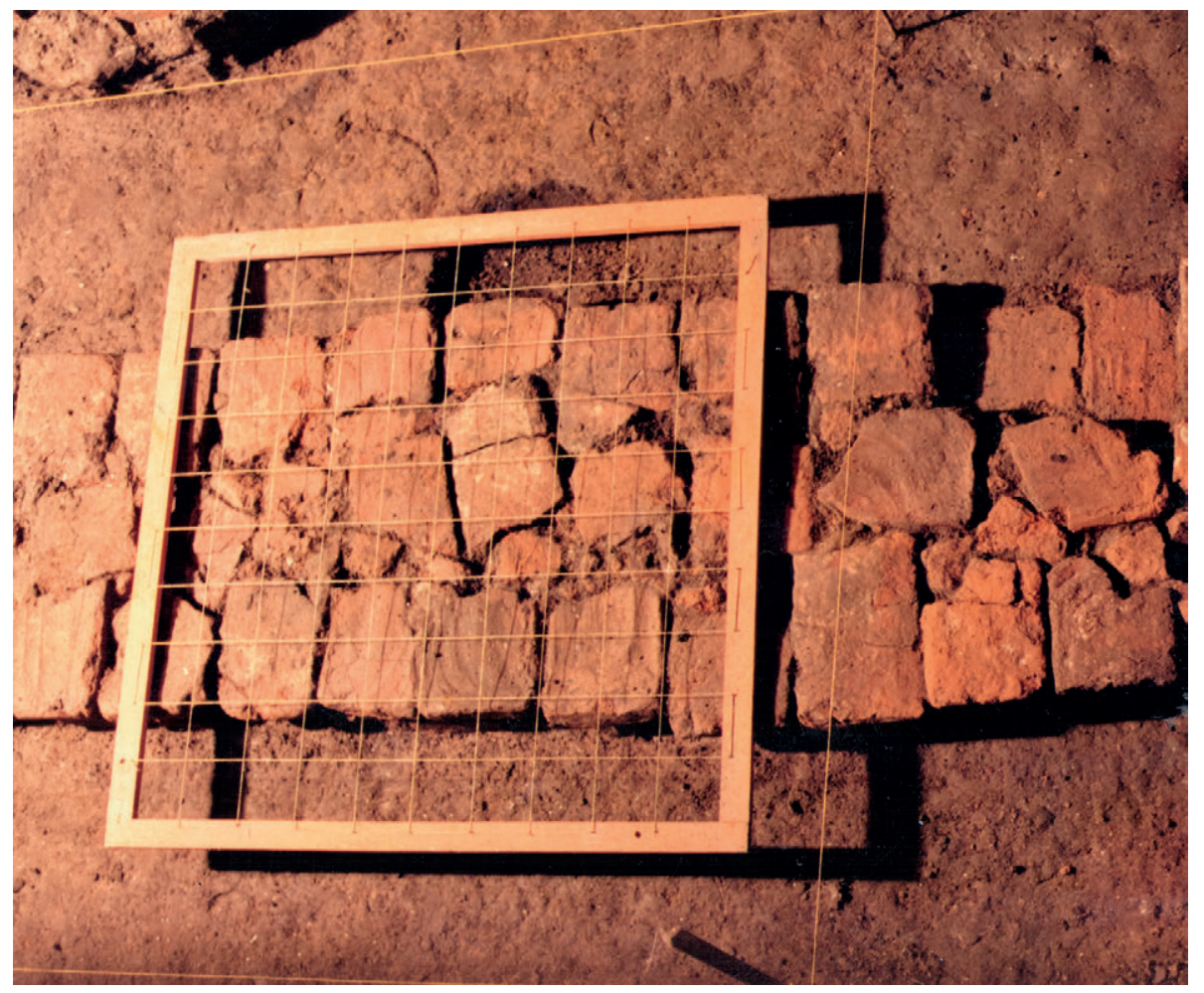

Fig. 7. Detalle de uno de los agujeros de poste cortado por un cimiento fechado para antes de 1740 , los ladrillos fragmentados medían en origen $40 \times 20 \times 5 \mathrm{~cm}$.

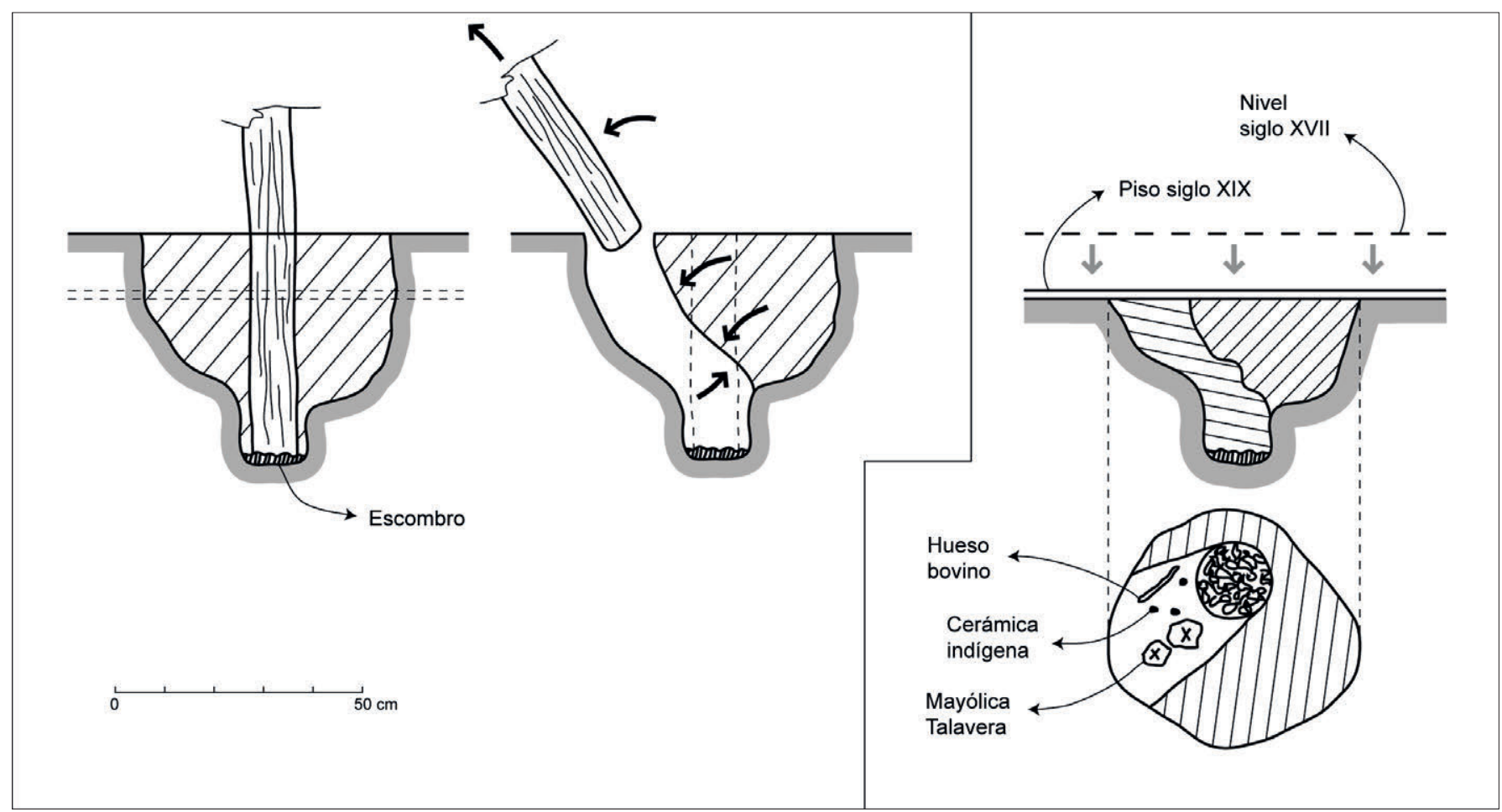

Fig. 8. Planta y corte de un agujero de poste hallado debajo de la Imprenta Coni, con la reconstrucción del poste que fue retirado produciendo la estratigrafía interna. 
orientada más allá de los documentos para su fundación, que si bien dice que también era norte-sur no se explica porqué hubo que rectificarla en 1608. Es posible que la diferencia no haya sido mucha, o que los vecinos y tal como sucedió incluso hasta finales del siglo XVIII no respetaban algunas de las calles apenas delineadas, o que realmente el trazado era un eufemismo y cada quien puso su casa donde pudo y quiso y luego fue necesario arreglar eso ante las autoridades en España, que era ante quien se enviaban los planos ${ }^{3}$. Es decir, en este caso es evidente que la línea de agujeros de postes está orientada y es preexistente al muro. Luego veremos que la orientación podría indicar su construcción dentro de la traza hispánica de manzanas regulares, dándonos una fecha. Por otra parte las estructuras indígenas de cuero relevadas en el siglo

${ }^{3}$ Las Actas del Cabildo de Buenos Aires, están llenas de pleitos entre vecinos y el Cabildo por este motivo, quizás el problema más grave que tenía la ciudad que crecía de manera poco regular.

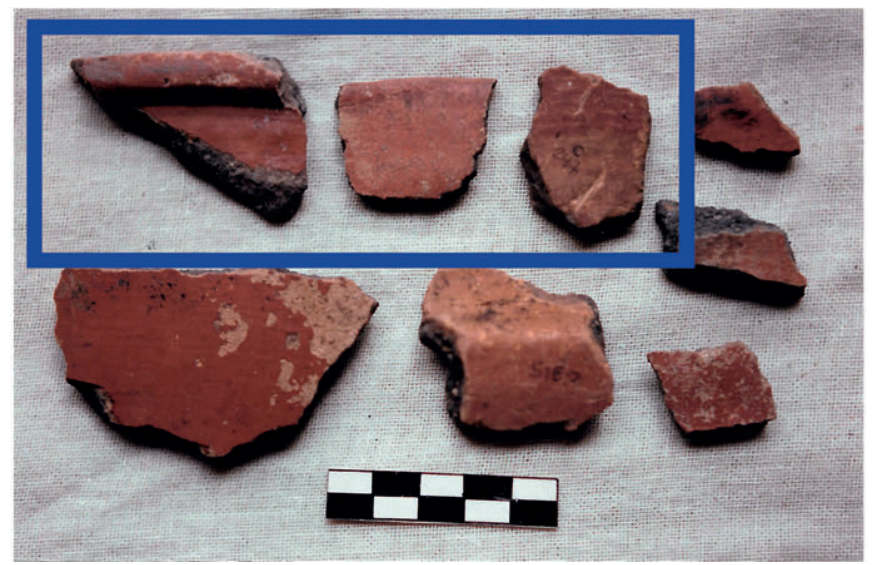

XIX en Patagonia y Pampa, aunque alejadas de la ciudad, también estaban orientadas según los puntos cardinales.

Dijimos que en uno de esos agujeros se encontraron en su interior cinco fragmentos cerámicos que muestran la convivencia del tipo Monocromo Rojo de tradición indígena regional con dos mayólicas españolas, una blanca y la otra con decoración en cobalto azul (Schávelzon 1995) (Fig. 9). Las tres primero citadas no son cerámicas indígenas precolombinas aunque su tradición sí lo es, pero fueron hechas en torno y con bordes imitando formas europeas por lo que su asociación a mayólicas españolas del siglo XVII es coherente. Si la casa que cortó y rellenó los agujeros se hizo antes de 1740, resulta adecuado que las cerámicas sean precedentes aunque sin saber la fecha de los agujeros en sí mismos. Esa excavación mostró una fuerte presencia de elementos indígenas o al menos de una tradición indígena no habitual en la ciudad posterior (Fig. 10).

Fig. 9. Cerámica Monocroma Roja del agujero de poste de la Imprenta Coni posiblemente del siglo XVII tardío (Schávelzon 1995: 52).
Fig. 10. Presencia indígena en la Imprenta Coni: manos de mortero de moler maíz (Schávelzon 1995: 22).

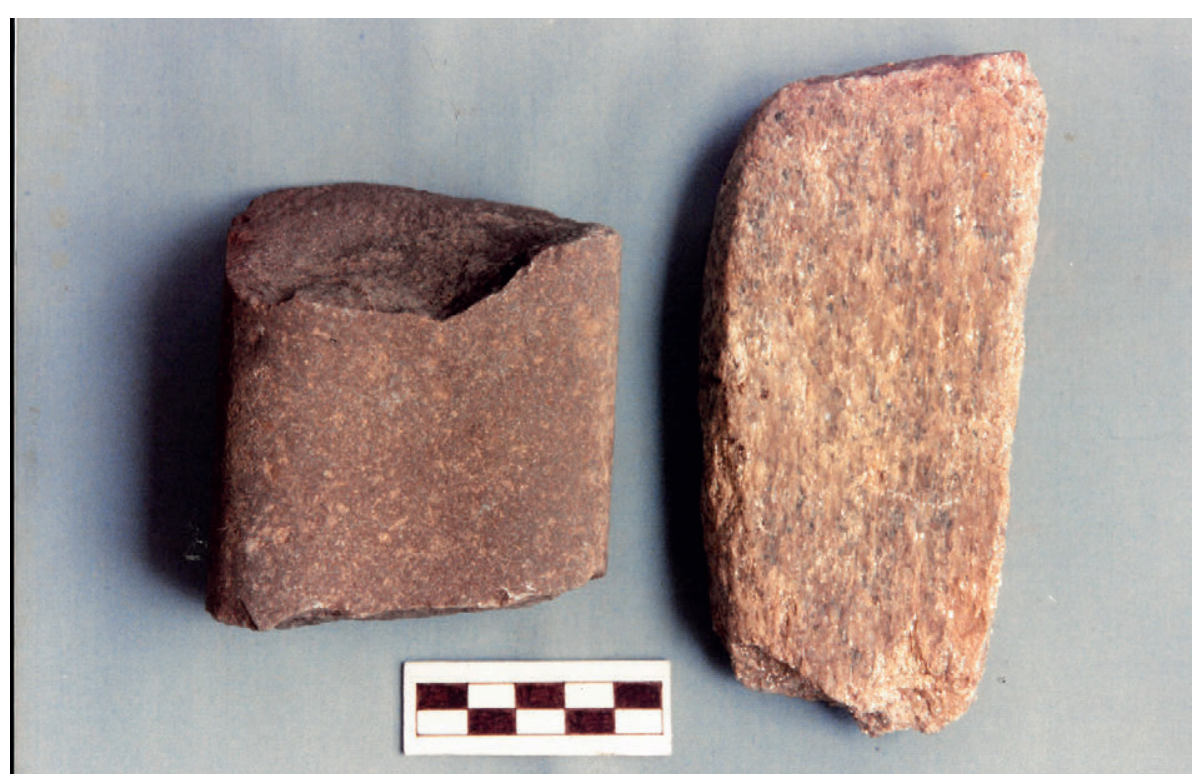




\section{LA CASA DEL VIRREY LINIERS}

La excavación hecha en la calle Venezuela 460, más reciente, llevó a encontrar otros tres agujeros de poste de este tipo (Hernández De Lara, Odlanyer y Schávelzon 2014). Aquí la situación fue diferente ya que no pudo abrirse una superficie amplia por el uso actual del sitio. De esa manera se hallaron dos en un lado y otro cuya relación no pudo ser encontrada al quedar muchos metros entre ellos sin excavar. Pero los dos primeros citados estaban alineados norte-sur. Uno de los agujeros, el aislado (aislado debido a la forma de excavación), fue encontrado en una trinchera de tres metros de largo por uno de ancho en el centro del patio de la casa actual, suponiendo que allí estaría el aljibe, lo que no fue así (Fig. 11). Resultó interesante que el estrato que cubría el agujero de ese poste mostraba los rasgos culturales típicos del ejido de la ciudad inicial: restos grandes de bóvidos y cerámica española del siglo XVII, lo que indica que al menos ese era anterior a ese evento (Fig. 12).

Los otros dos pozos se excavaron en una superficie mayor iniciada como Open area aunque no se pudo lograr ampliar totalmente la superficie, ubicada al noroeste del patio. El sector estaba alterado por muros diversos aunque la mayoría eran de los siglos XVII e inicios del XVIII. Pese a estar ambos agujeros

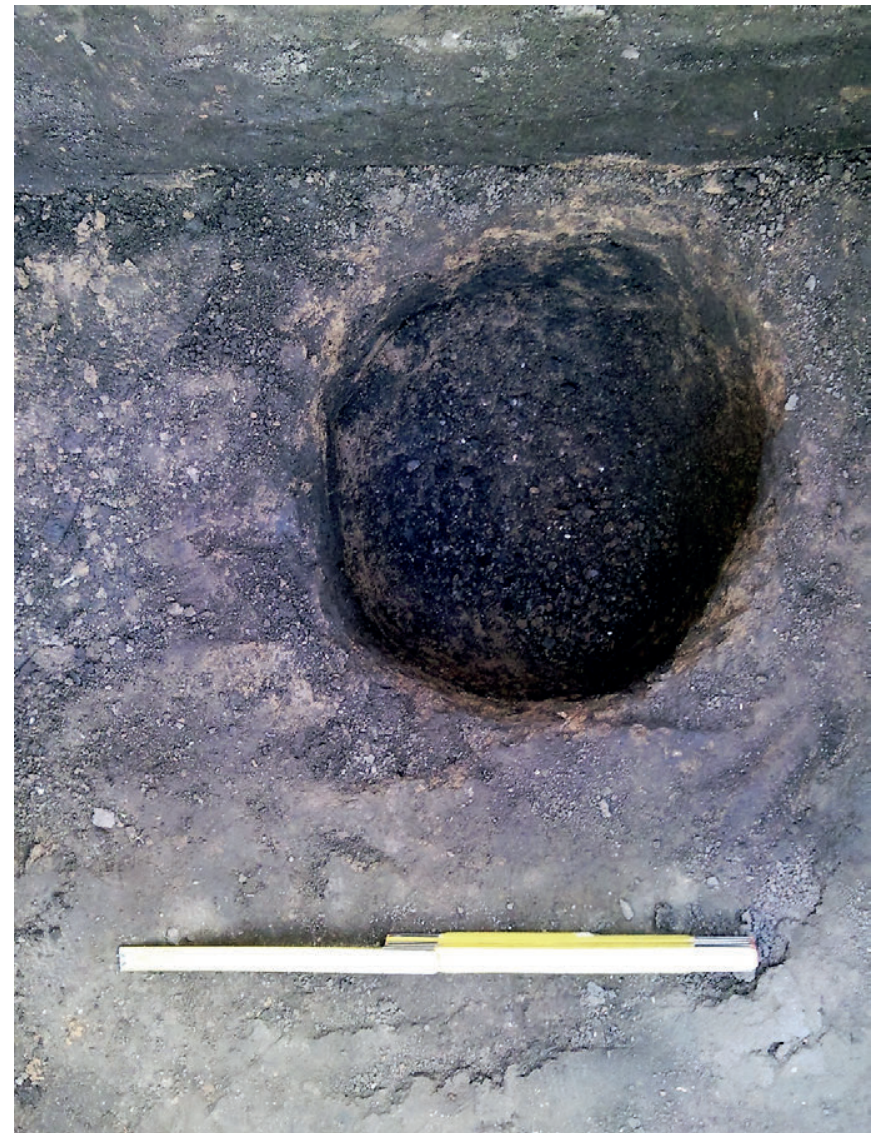

Fig. 11. Vista vertical del agujero de poste de la Trinchera Central, nótese la parte inferior redondeada.

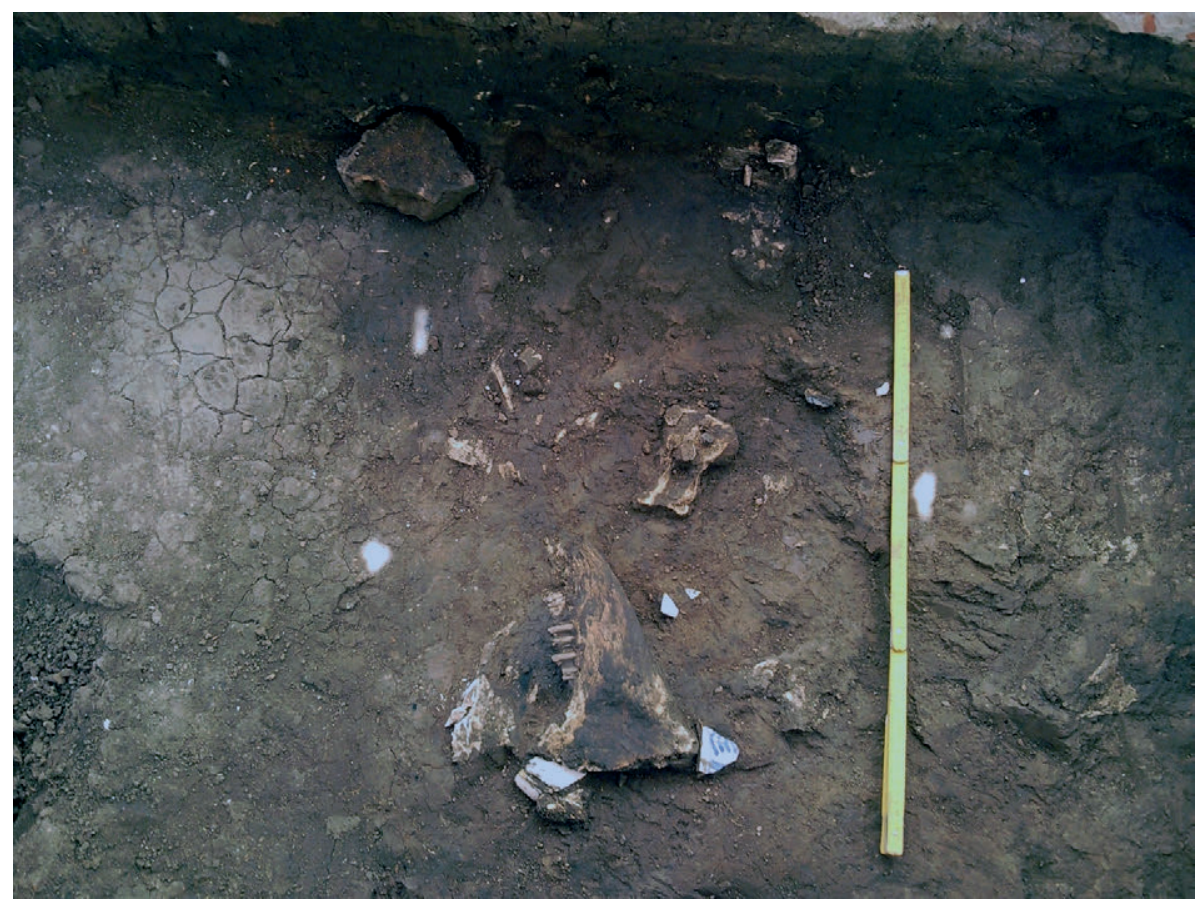

Fig. 12. Contexto del siglo XVII que cubría el agujero del poste de la Fig. 12, con mayólicas españolas y restos de un vacuno. 
ubicados sobre una línea paralela a los muros de la antigua casa tenían diferente forma: uno era ligeramente ovalado (Fig. 13 y Fig. 14) mientras el otro era más ancho arriba y más angosta abajo, es decir con forma de embudo (Fig. 15, Fig. 16 y Fig. 17). Igualmente ambos tenían menor profundidad que en origen ya que toda la superficie de ese patio había sido rebajada en el siglo XX para hacer un piso de cemento, bajando el nivel uno 30 o 40 centímetros. $\mathrm{Y}$ es posible que antes ya hubiese habido una acción similar llevándose toda evidencia del siglo XIX y la mayor parte del XVIII. $\mathrm{Y}$ si bien nos quedaron cimientos de esos dos siglos, el contexto de la tierra entre muros era básicamente del XVII.

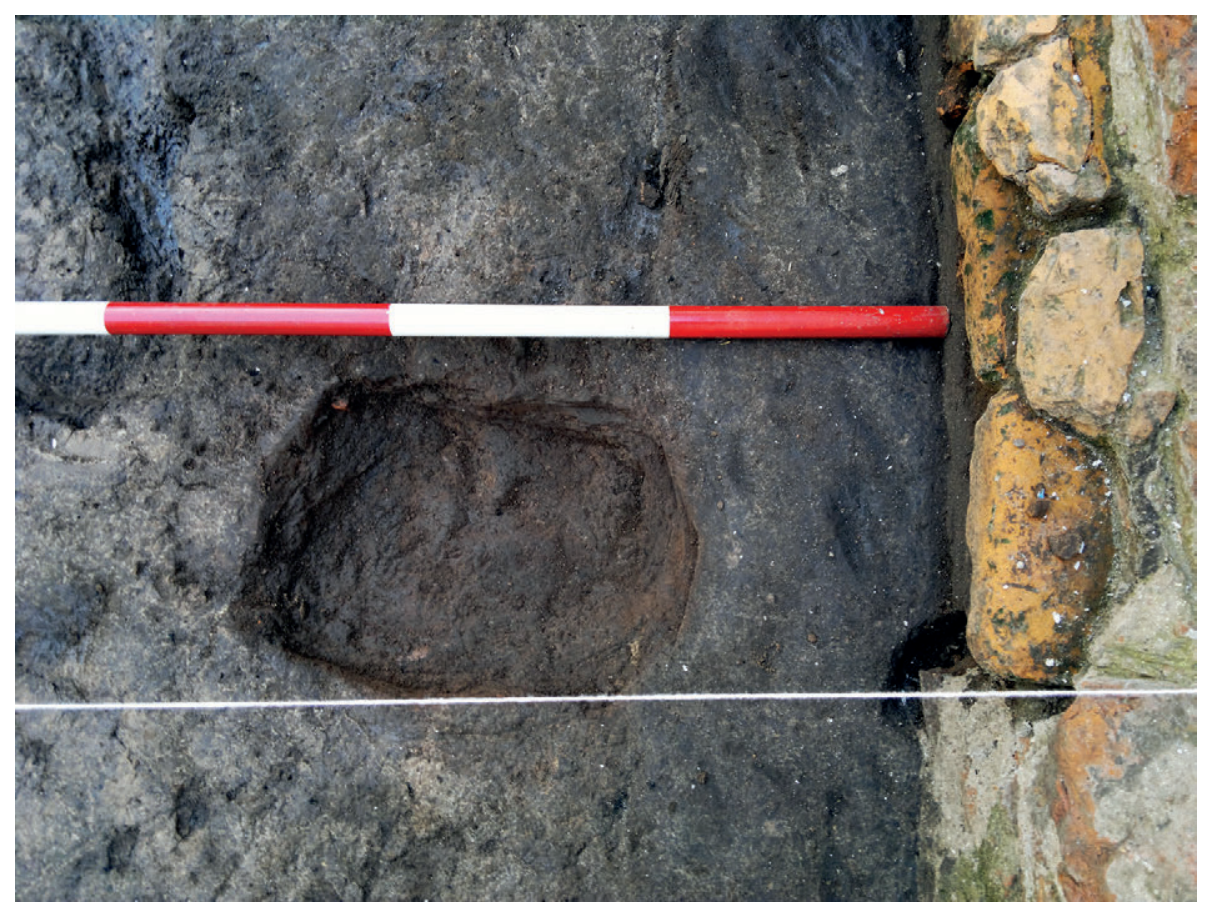

Fig. 13. Pozo de forma ligeramente oblonga con marcas de remoción de un poste en la Casa del Virrey Liniers.

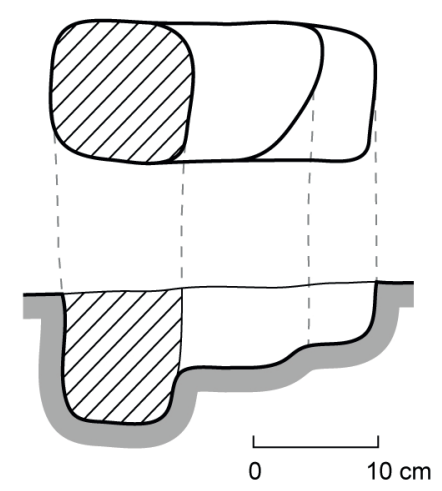

Fig. 14. Detalle del agujero mostrando haber sido asiento de un poste cuadrangular que fuera removido. 


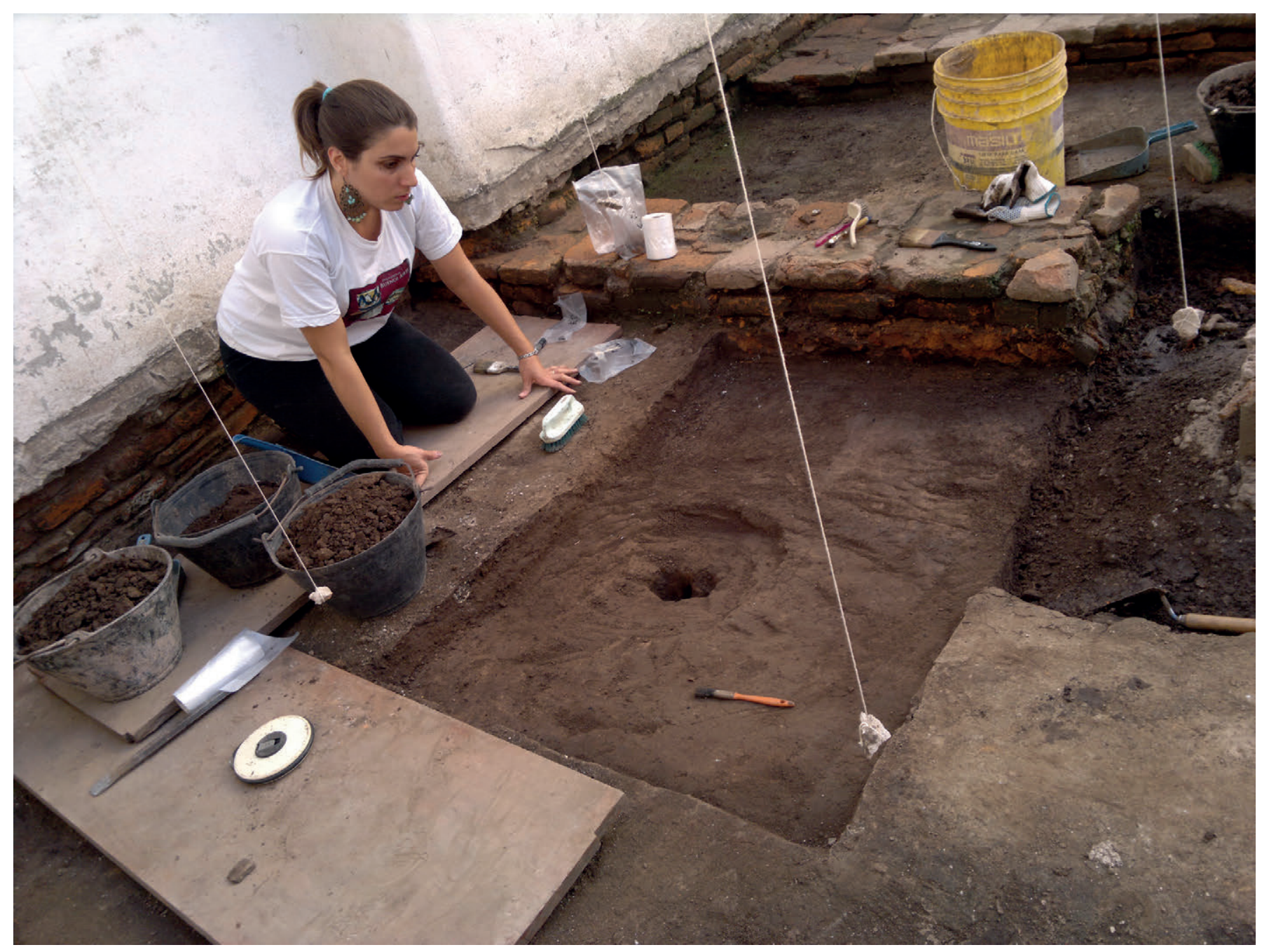

Fig. 15. Agujero de poste ubicado al norte, con su peculiar forma de embudo.

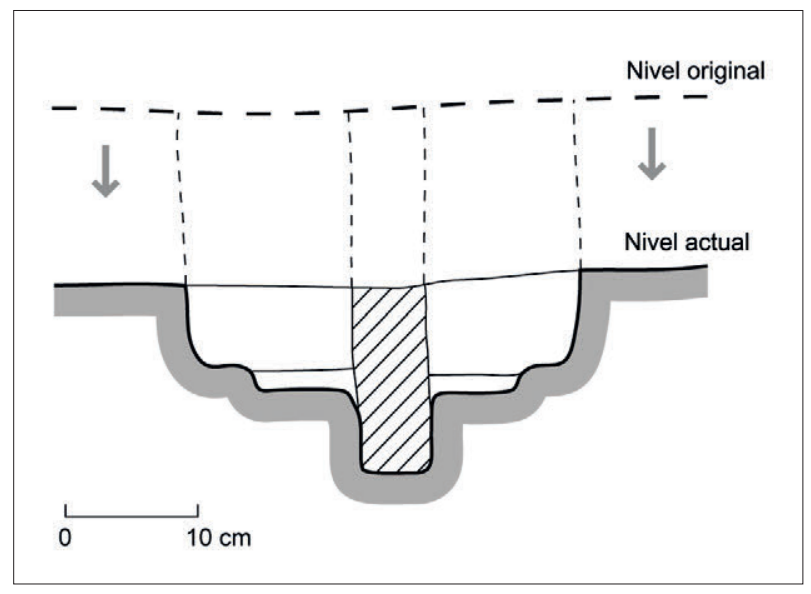

Fig. 16. Detalle del agujero de poste ubicado al norte en la Casa del Virrey Liniers. 


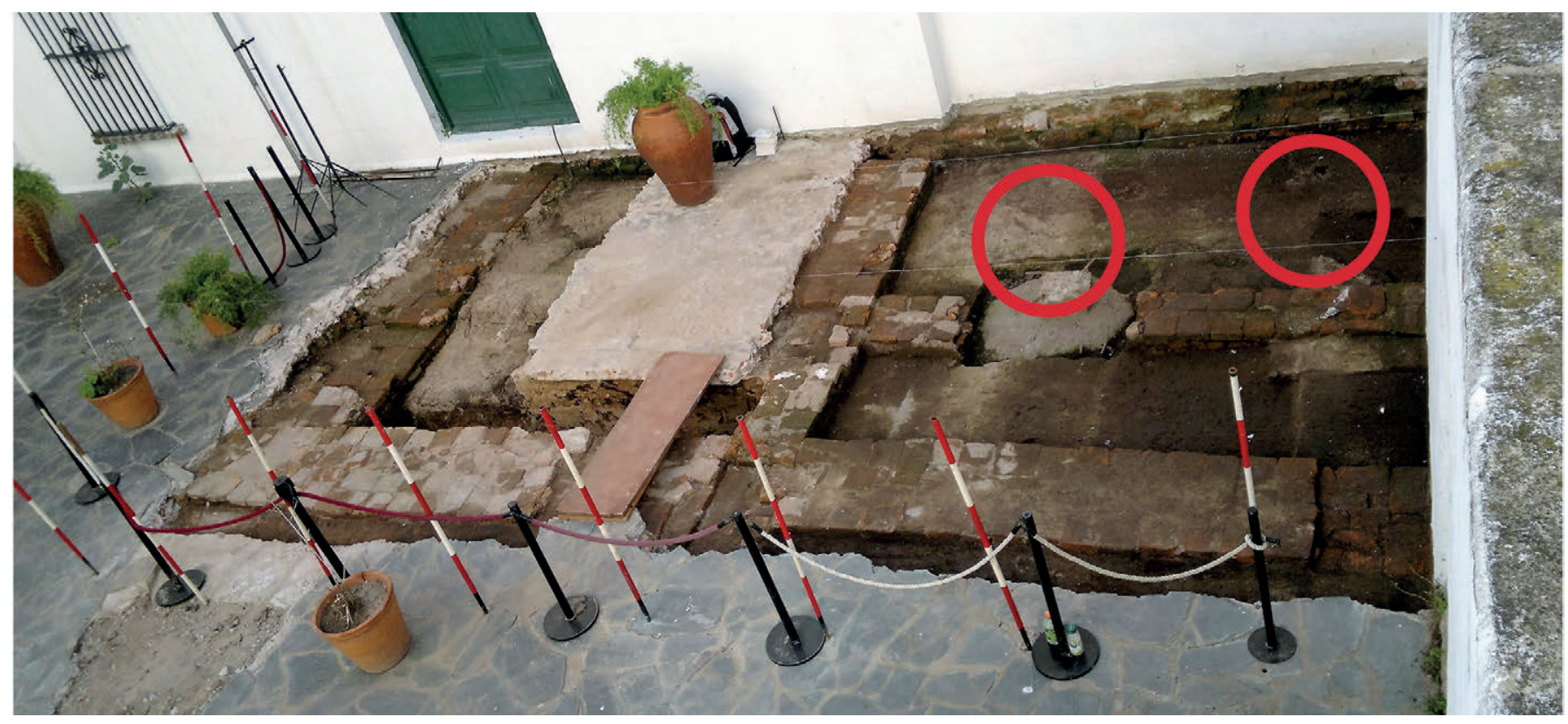

Fig. 17. Vista del Sector Oeste de la excavación del patio de la Casa del Virrey Liniers, con la ubicación de los dos agujeros sobre la misma línea norte-sur.

\section{LAS HIPÓTESIS}

Desconocemos, como ya se ha dicho, la función que cumplieron estos muy probables postes enterrados, las que pueden ser muchas. A la vez las evidencias son aun pocas para avanzar en las interpretaciones. Pero hay posibilidades que se plantean como probables: 1) que sean evidencias de toldos indígenas predecesoras a la ciudad española, o de sus primeros tiempos de existencia, 2) que sean postes de ranchos ${ }^{4} \mathrm{y} / \mathrm{o}$ de galerías frontales o laterales de casas anteriores a la Real ordenanza de $1784^{5}$, y 3) que sean parte del sistema de andamios para construir muros, lo que parece coincidir con ninguna pared encontrada cerca.

\section{Tolderías ${ }^{6}$ indígenas}

La presencia indígena en la ciudad y la posible existencia de su propia arquitectura son temas complejos.

\footnotetext{
${ }^{4}$ Rancho: construcción caracterizada por su pobreza de cualquier época o lugar, generalmente se lo concibe como hecho con postes y ramas, a veces cubiertos de barro (el "bahareque" del Caribe).

${ }^{5}$ Ordenanza real que obligó a construir las casas sobre la línea municipal delimitando así las manzanas urbanas, construyendo fachadas importantes y sin galerías. Fue la llegada de la ciudad Ilustrada a América.

${ }^{6}$ Toldo, toldería: términos usados en Argentina para identificar un tipo de construcción hecho por la población originaria mediante postes clavados y cubierta por cueros cosidos entre sí, comunes desde la región pampeana -por ende Buenos Aires- hasta Tierra del Fuego, similares todas ellas aunque con detalles regionales.
}

Sabemos que vivieron en la ciudad, que ocuparon el territorio antes de la llegada de Pedro de Mendoza con quienes tuvo que luchar y su presencia está documentada hasta en los censos aunque en muy bajos porcentajes. Llamó la atención a los ilustradores viajeros en los inicios del siglo XIX que los retrataron ya como algo exótico desde la mira Romántica. El tema ha sido estudiado por la antropología desde hace un siglo y existe un extenso y exhaustivo estudio de la arquitectura de toldos de cuero sostenidos por postes desde la Pampa hasta Tierra del Fuego, hecho con detalle (Casamiquela 2000). No vamos a redundar en ello más que para una descripción muy amplia de los toldos hechos cueros de caballo o animal cosidos entre sí, sostenidos por hileras paralelas de postes enterrados en el suelo, formando tiendas de mayor o menor dimensión interna. Si bien sobre la ciudad de Buenos Aires el tema no ha sido analizado, sabemos por los censos que existían estas construcciones a no muchas cuadras de Plaza de Mayo: el Censo de la ciudad que se hizo en 1738 habla de la existencia de "ranchos de cuero" en la actual calle Viamonte (Ravignani 1920-55; Schávelzon 1994a), es decir a sólo cuatro cuadras de la central Plaza de Mayo. Para esa época la población indígena censada en la ciudad era siempre menor al $5 \%$, posiblemente haya sido el $2 \%$ según algunas fuentes. Pero recordemos la dificultad de usar este método para calcular ya que 
al circular para vender productos era casi imposible hacerlo. Además que para hacer trabajos ocasionales en las grandes obras públicas, tal como sucedía con los guaraníes a los que los jesuitas los traían masivamente (hasta dos mil personas por vez), los que no eran siquiera considerados numéricamente para los censos. Se supone que muchos de ellos vivirían en las rancherias $^{7}$ de las iglesias. Tampoco tenemos números exactos de los indígenas esclavizados o reducidos, lo que si bien era en buena forma ilegal igualmente los habían. En estos casos la cantidad era mucho mayor de lo censado pero no entraba en los documentos, los que estaban preocupados por el número de vecinos y de propiedades para poder tasar impuestos.

Quizás la primera descripción de estos "toldos de cueros" es la que dejó el viajero padre Sánchez Labrador hacia 1770:

"De las pieles de los baguales" fabrican también sus casas. Estas no son otra cosa que unas grandes tiendas, o toldos, altas, cuadradas, y algo arqueadas en el medio. Para el techo cosen veintiséis cueros de caballo, dejando el pelo hacia afuera para que corra el agua cuando llueve" (Sánchez Labrador 1910).

Un dato que nos parece sustantivo que trae también la descripción que hizo este religioso es cuando indicó que esas viviendas estaban orientadas según los puntos cardinales, o al menos que "dejan dos puertas, una al Oriente y otra al Poniente; o una al Norte y otra al Sud, según les viene mejor a los dueños" (Fig. 2), lo que coincide con lo encontrado en los ejemplos anteriores de agujeros de postes. Otra descripción muy cercana en el tiempo a la referida la dejó Félix de Azara para las cercanías de la ciudad en los finales del siglo XVIIII:

"Para hacer su toldo o casa, clavan en la tierra, apartados como seis palmos, y en línea, tres palos (...) el del medio largo como diez palmos, los otros menos, y todos con horquillas en la punta. A distancia de cuatro a seis varas clavan otros tres palos idénticos; de éstos a aquéllos ponen en las horquillas tres cañas o palos horizontales y sobre éstos tienden pieles de caballo: esta es la casa para una familia, pero si tienen frío acomodan otras pieles verticales en los costados" (Azara 1923: 220).

\footnotetext{
${ }^{7}$ Rancherías: sitio que las órdenes religiosas tenían cerca de sus iglesias en donde vivían los esclavos, de la palabra rancho cuyo plural es rancherío.

${ }^{8}$ Caballos o vacunos en estado salvaje o indómito en el habla regional.
}

Finalmente hay un detalle que podría ser importante, surgido al observar que al menos en la Imprenta Coni la hilera de postes es una sola y en este tipo de toldos son varias paralelas entre sí. Las fotografías muestran que los postes del frente son mucho más altos que los demás porque debían permitir a la gente estar parados; en otros la hilera del centro es la más alta. Eso implica que para enterrarlos fue necesario hacer agujeros más profundos y hasta más anchos unos que otros. Como en ambos casos, Coni y Virrey Liniers, los suelos originales fueron rebajados hasta en $40 \mathrm{~cm}$, lo lógico es que se hayan conservado sólo evidencias de los postes más altos y por ende con pozos más profundos (Fig. 8). Esto implicaría que quizás otros agujeros cercanos hayan desaparecido en esas nivelaciones del terreno. Es claramente una suposición razonable en función del proceso de alteración que produjo la nivelación de casi toda la ciudad en el siglo XIX.

\section{Galerías y ranchos previos a la Real ordenanza de 1784}

La ciudad tenía desde el inicio, en forma mayoritaria hasta el siglo XVIII, ranchos de todo tipo. Si bien así se identificaba cualquier construcción modesta de pocos recursos económicos, nos interesan los de paredes de postes y ramas, recubiertos o no con barro. Las paredes estaban hechas con una hilera de palos verticales entre los cuales se entretejían ramas, que podían o no estar recubiertas por barro embostado 9 o blanquea$d_{a s^{10}}$. Era común que los toldos fuesen indígenas y los ranchos de criollos, pero no necesariamente es así; un criollo difícilmente viviría en un toldo, pero sí se usaba despectivamente la palabra rancho para cualquier cosa que no fuese una construcción de mampostería de ladrillo, crudo o cocido. El Censo de la ciudad hecho en 1738 hablaba de la presencia de "ranchos", "rancho de paja con adobe crudo" y "ranchito de paja" como categorías habituales de arquitecturas que eran entendidas por las autoridades (Fig. 4). Es decir, sí había en la ciudad construcciones que dejaban marcas en forma de agujeros de postes.

\footnotetext{
9 Embostado: sistema usado para revocar ramas o cañas en que el barro se mezcla con "bosta" (detritos) de caballos o vacunos por su alto contenido vegetal y capacidad de darle rigidez a la mezcla.

10 Blanqueado: sistema de recubrimiento de paredes mediante una mano de cal casi líquida, común hasta el siglo XVIII porque el producto era caro como para un revoque grueso. Las sucesivas capas, año tras año iban generando una protección de cierta calidad e incluso pintarla.
} 
La presencia de pilares, es decir postes recios generalmente cuadrados ubicados en las entradas de casas formando un pórtico, es también motivo de interés, pero hay dos detalles que nos lleva a descartarlos: generalmente tenían bases de ladrillos para evitar la putrefacción de la madera en la tierra húmeda. Y la Real Ordenanza de 1780 los acabó al menos al frente ya que si bien era posible construir en el interior del terreno, necesariamente había que hacer una fachada plana hacia la calle (Schávelzon 1994b).

\section{Andamios para construcción}

La posibilidad de que sean agujeros hechos para los postes de los andamios fue una de las primeras hipótesis ya que es imposible hacer muros sin ellos. Pero hay un inconveniente en estos pocos datos: deben correr paralelos a él y a una distancia de cerca de un metro, cosa que no sucede. Pero es un tema que no debería minimizarse ya que para construir en altura son necesarios y al sacarlos dejan una fila de agujeros de postes separados y alineados.

\section{CONCLUSIONES}

En los dos hallazgos que hemos descrito creemos que se trataba, sea de toldos indígenas o de ranchos criollos. Que fueron construidos con postes de madera y algunos de ellos en su interior se los afirmó con tierra conteniendo fragmentos de cerámicas, ladrillos o huesos, de ahí su mayor ancho. Que hayan existido muchas otras construcciones que dejaron evidencias de agujeros de poste no creo que pueda dudarse pese a la poca evidencia arqueológica aun encontrada, pero determinar quienes vivieron -indígenas, criollos, blancos pobres, esclavos - es imposible actualmente. La presencia estable de construcciones indígenas es un tema que generará enormes polémicas ya que rompe la imagen de la ciudad tradicional, pero en las excavaciones se han encontrado desde cerámicas pre y poshispánicas claramente indígenas, incluso sin torno sin o con poca influencia hispánica hasta manos de morteros de piedra para moler, la que se traía de largas distancias. ¿Estamos ante algunas de las más antiguas arquitecturas locales? ¿Estamos ante la presencia de la ocupación indígena en el inicio del período hispánico? ¿Estamos ante evidencias de construcciones de material perecedero de muy bajos recursos económicos que no habíamos visto ni imaginado?

\section{AGRADECIMIENTOS}

Osvaldo Mondelo que nos permitió reproducir sus fotografías, a Stanley South que me facilitó sus planos de viejos años y a Rodolfo Casamiquela por todos sus conocimientos del tema, y a ambos porque vieron la posibilidad de que hubiera restos de ocupación indígena en la ciudad expresada en evidencias de arquitectura, y lo comentaron en la década de 1990.

A la amistad de Agustín Azkárate y su equipo que han aplicado el método de Open area en el país con éxitos reconocidos en Sancti Spíritu. Los dibujos han sido hechos por Francisco Gireli.

\section{BIBLIOGRAFÍA}

Azkárate, A. 2013: Informe final del proyecto: Localización del primer asentamiento español en el Río de la Plata. Puerto Gaboto, Provincia de Santa Fe, Universidad del País Vasco, Manuscrito.

Azara, F. de 1923: Viaje por la América Meridional, vol. II. Espasa-Calpe, Madrid.

Baker, P., 1993: Techniques of Archaeological Excavations, B. T. Batsford, Londres, tercera edición.

Casamiquela, R. 2000: Temas patagónicos de interés arqueológico VI. Análisis etnográfico de la morfología del toldo tehuelche y sus derivaciones etnológicas (hacia una 'retro-etnología'), Intersecciones en Antropología $\mathrm{N}^{\mathrm{o}} 1$, pags. 3-33.

Cocco, G., Letieri, F. y Frittegotto, G. 2011: El descubrimiento y estudio del fuerte de Sancti Spiritus, América no. 20, pp. 69-85.

Hernández De Lara, Odlanyer y Schávelzon, D. (eds.) 2014: Casa del Virrey Liniers: hallazgos arqueológicos, Aspha, Buenos Aires.

Harris, E. 1991: Principios de Estratigrafía Arqueológica, Editorial Crítica, Barcelona.

Igareta, A. y Malbrán, A. 2013: Breve reseña de la arqueología histórica argentina, Simposio Román Piña Chan: visiones de la arqueología en el siglo XXI, México, pp. 494-510 (en prensa).

Mondelo, O. 2012: Tehuelches: danza con fotos, edición del autor, Buenos Aires.

Letieri, F., Cocco, G., Frittegotto, G. y Astiz, M. A. 2010: Investigaciones arqueológicas sobre el primer asentamiento español en la cuenca del Río de la Plata: el fuerte Sancti Spíritus (1527-1529). En: Arqueología de ciudades americanas del Siglo XVI, H. Chiavazza y C. N. Ceruti editores. Facultad de Filosofía y Letras, UNCuyo, Mendoza.

Ravignani, E. 1920-55: Padrón de vesinidad de esta ziudad y su juriz.on hecho por los diputados nombrados para eso..., Documentos para la historia argentina, Volumen X, Instituto de Investigaciones Históricas, Buenos Aires.

Rafinno, R. e Igareta, A. 2004: Arqueología histórica en la Argentina: antecedentes y perspectivas de su desarrollo, Investigaciones y ensayos 54, pp. 57-77.

Sánchez Labrador, J. 1910: Paraguay Católico, Coni Hnos, Buenos Aires, 1910.

Schávelzon, D. 1994a: La casa colonial porteña, notas preliminares sobre tipología y uso de la vivienda, Medio ambiente y urbanización no 46, pp. 69-83.

Schávelzon, D. 1994b: Centro y periferia en el padrón de 1738, Vivienda y vida cotidiana colonial: una visión arqueológica, Trabajos de Crítica no 55, s/p, Instituto de Arte Americano, www.iaa.fadu.uba.ar/publicaciones/ critica/0055.pdf

Schávelzon, D. 1995: Arqueología histórica de Buenos Aires (III): excavaciones en la Imprenta Coni, Editorial Corregidor, Buenos Aires. 